\title{
Contradictory (forward) lifetime effects and the non-future tense in Mandarin Chinese
}

\author{
Sherry Yong Chen \& E. Matthew Husband*
}

\begin{abstract}
Lifetime effects refer to the inferences about the life/death of the individual in sentences with individual-level predicates like 'Mary is/was blue-eyed'. In English, contradictory lifetime inferences arise when the subject denotes one living and one dead individual (e.g. Saussure ${ }_{\text {dead }}$ and Chomsky living $_{\text {\#are/?? were both }}$ linguists.), but no such inferences arises in Mandarin Chinese, a language that has been considered "tenseless" due to the lack of past tense morphemes. This paper investigates the online processing of contradictory lifetime effects and presents additional empirical observations about "forward lifetime effects", which suggest that both covert past tense and tenseless accounts of Chinese are inadequate for capturing temporal interpretations in this language; instead, finite clauses in Chinese display a Future/Non-Future distinction and are likely to possess a tense node. We discuss our findings in relation to the typology of tense as well as implications for other superficially tenseless languages.
\end{abstract}

Keywords. Tenselessness, lifetime effects, sentence processing, Mandarin Chinese

1. Introduction. The grammatical expression of time has been claimed to be "a universal property of language" (Lecarme, 2004, p. 7), but there are cross-linguistic differences concerning its morpho-syntactic construction. Tense is one grammaticalised form of temporal relation, which seems to be overtly encoded in some languages but not the others, leading to a distinction between the tensed and so-called "tenseless" languages. For example, the English past tense copular was in (1) clearly locates the event of Mary's studying in the past, whereas the Chinese counterpart in (2) only contains an aspectual marker zai, rendering the sentence compatible with either a past or a present interpretation indicated by the gloss:

(1) Mary was studying.

(2) mali zai xue-xi

Mary PROG study

'Mary was/is studying.'

Such cross-linguistic variation brings up several interesting issues: How do English and Chinese differ in terms of temporal interpretation, given that one has overt tense marking and the other does not? Does Chinese have a covert T node nonetheless, even though tense is not morpho-phonologically realized in this language? In this paper, we engage with questions of how different languages encode temporal relations, and how such temporal information is processed during real-time language comprehension. In particular, we aim to pin down the details of the Chinese tense system, traditionally classified as an example of a tenseless language, by showing that Chinese clauses may possess a phonologically null tense which bears the [NON-FUTURE] feature.

\footnotetext{
* The paper is partially based on the first author's MPhil thesis. We thank the audience at the $22^{\text {nd }}$ Architectures and Mechanisms for Language Processing Conference, the Tenselessness Workshop, and the $92^{\text {nd }}$ LSA Annual Meeting for their helpful comments. Authors: Sherry Yong Chen, MIT (sychen@mit.edu); E. Matthew Husband, University of Oxford (matthew.husband@ling-phil.ox.ac.uk).
} 
2. Tense and Tenselessness. The literature on tense is enormous, but in general, tense is defined in syntactic and semantic terms. Dating back to Reichenbach (1971), the semantics of tense can be understood as situating event time in relation to speech time and reference time, although later theories have drifted away from representing tenses as configurations of temporal points in favour of a view that treats tense as the relation between temporal intervals (e.g. Dowty, 1979; Klein, 1994). Meanwhile, syntactic tense concerns a tense node in the syntactic structure of a language, which may be realized covertly or overtly: overt tense is achieved via morphological marking, e.g. a tense morpheme, whereas covert tense is phonologically empty but still provides a feature-checking mechanism for tense features, such as [PAST] and [NON-PAST]. We take the view that syntactic tense refers to a syntactic category heading its own projection, Tense, which maps onto a corresponding semantic tense, and vice versa. That is to say, evidence for semantic tense should be taken to transparently reflect the syntactic structure (transparent mapping hypothesis, a lá Matthewson (2001)).

The term "tenselessness" is typically used for languages that lack overt marking of tense (e.g. Smith, 2008). Following this view, the existence of languages with no morpho-phological marking for tense challenges the empirical motivation for Tense as a functional category in the Principles and Parameters framework in its Minimalist incarnation (Ritter \& Wiltschko, 2014). However, it is theoretically possible that tense is not morpho-phonologically realized, but a Tense Phrase still exists in the syntax of these languages. This notion of covert tense has triggered much theoretical debate with regard to the syntactic structure of tenseless languages and, more broadly speaking, the universality of a Tense Phrase.

2.1. TENSE IN CHINESE. The possibility that syntactic tense may be covert raises the question of whether languages like Chinese are "tenseless" only superficially. It is widely acknowledged that Chinese lacks overt marking of past tense in its inflectional morphology (C. T. J. Huang, 1998; Klein, 1994; Klein, Li, \& Hendriks, 2000; J. W. Lin, 2003, 2006, 2010, 2012; Smith \& Erbaugh, 2005; a.o.). There is general consensus that with the bare copular shi, both past and present readings are available, although a future interpretation is excluded:

$\begin{array}{llll}\text { mali shi yi-ge } & \text { hao } & \text { ren. } \\ \text { Mary COP } & \text { one- CL } & \text { good } & \text { person } \\ \text { 'Mary was/is a good person.' } & \end{array}$

(3) involves no overt marking of tense, nor does it seem to restrict the temporal interpretation to the past or the present (in relation to the time of utterance). However, it remains unclear if a tense node needs to be assumed in order to account for these observations, and if so, what features it should specify.

Until recently, theoretical discussions of the Chinese tense system largely focused on whether or not the system is tenseless or has a covert past tense. Arguments from both sides rely mainly on indirect evidence, such as whether there is a finiteness distinction in Chinese (T. H. Lin, 2015; Grano, 2014), which is in fact neither sufficient nor necessary for a Tense Phrase (see for example, Grano 2017). Most notably, J. W. Lin (2006) argues that not only does Chinese have no morphological tenses, but there is "no need to resort to covert features under an empty tense node" in the syntax of Chinese (p. 49). Smith (2008) also argues that tensed languages have a Tense Phrase in syntax while tenseless languages only have a syntactic Aspect Phrase; under this view, Tense Phrase is not universal, and syntactically Chinese is truly tenseless. However, arguments in favour of the tenseless analysis are unsatisfactory as they essentially rely on the 
claim that a tense node is unnecessary; no empirical evidence has been raised against the covert tense analysis.

Alternative views which assumes a covert (past) tense in Chinese have been offered: based on some parallel observations between Chinese and Dutch, a tensed language which requires agreement between a past temporal adverbial and a past tense morpheme, Sybesma (2007) argues that the T node in Chinese is a mere agreement morpheme, agreeing with temporal adverbs. However, in Sybesma's proposal, it is unclear what exactly the feature of the tense node is if it is not a temporal one. Additionally, T. H. Lin $(2011,2012,2015)$ demonstrates that there is indeed a Finite/Non-finite contrast in the clausal complements of modals in Chinese, which makes object fronting possible only if it is from a finite clause (as in 4a), but impossible if it is from a non-finite clause (as in $4 b$ ):
a. Zhangsan shuo
Zhangsan say
'Zhangsan has eaten the hamburger.'
[Lisi hanbao ${ }_{i}$
b. \# Zhangsan yaoqiu
Zhangsan ask
[Lisi hanbao
[Lisi hamburger
chi-wan
eat-finish
Intended: 'Zhangsan asked Lisi to eat the hamburger.'

$\left.\mathrm{e}_{\mathrm{i}}\right] \quad$ le.

ASP

This shows that object fronting in Chinese is sensitive to the finiteness property of the clause, which, according to T. H. Lin (2015), may come directly from a tense node. That said, the finiteness property does not entail the existence of a T node; nor does it inform us of the specific tense system that Chinese may possess. While the tenseless analysis remains unsatisfactory, empirical evidence in support of a covert past tense is also still rather scarce.

While these lively exchanges offer much insight into the temporal interpretations available in Chinese, the debate about whether Chinese has a $\mathrm{T}$ node remains fundamentally unsettled. In addition, although Chinese continues to be widely cited as a classic example of tenseless languages, recent research has shed new light on a third possibility: Chinese may possess a tense node with a Future/Non-Future distinction (Chen, 2017; Z. N. Huang, 2015; Li, 2016; Sun, 2014). This hypothesis calls for a re-analysis of a class of so-called tenseless languages; a more fine-grained investigation of these languages is worth pursing as it has a broader bearing on certain fundamental issues, such as whether Tense Phrase is a universal syntactic category.

2.2. LifETIME EFFECTS. To engage with the debates about Chinese tense, we investigated the tense systems of English and Chinese by looking at a particular linguistic phenomenon: lifetime effects. An individual-level predicate in the present or past tense triggers an inference (though defeasible) about the life or death of an individual (Arche, 2006; Husband, 2012; Jäger, 2001; Kratzer, 1995; Magri, 2009; Mittwoch, 2008; Musan, 1995, 1997; Roy, 2013; Thomas, 2012):

$$
\text { Mary has blue eyes. } m \text { Mary is alive }
$$

John was from America. $\rightarrow$ John is dead

In (5) and (6), verbal tenses interact with temporal information in the nominal subjects. Since as early as Anderson (1973), it has been widely observed that the use of tense in the above examples seems to locate the time of existence of the nominal subject; the life or death of an individual can be clearly inferred, depending on the particular choice of tense that is combined with an individual-level predicate. 
More interestingly, Mittwoch (2008) observes that contradictory inferences arise when the subject NP denotes one living and one dead individual, as neither tense seems appropriate for the English copular $b e^{l}$ :

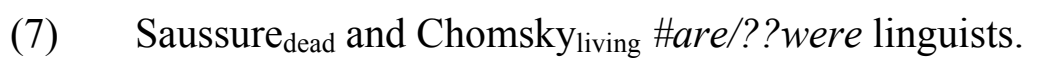

(8) This house was built for Bill Stevens, the actor, who died last year. The one over there belonged to his brother, John Stevens, the property tycoon; he now lives in America.

They \#are/?? were both very handsome.

Contradictory lifetime inferences relate closely to the interaction of temporal information in the nominal and verbal domains. Additionally, it provides a potential test for the tense systems that are available cross-linguistically. For example, do lifetime effects arise in "tenseless" languages such as Chinese, where there is no overt marking of the past tense? Introspection tells us that the answer seems to be no:
Zhangsan
Zhangsan
shi yi-wei
COP One-CL
yuyanxuejia.
linguist
'Zhangsan was/is a linguist.' $\nrightarrow$ Zhangsan is alive/dead.

In (9), if the listener has no prior knowledge of Zhangsan, they cannot immediately infer whether he is alive or dead but will have to wait for follow-up information before drawing an inference. This contrasts sharply with the intuition in (5) and (6), raising the question of what causes the lack of lifetime inference in Chinese. Furthermore, in (10) - the Chinese equivalent of (7) - no contradictory inferences seem to arise:

$\begin{array}{lllll}\text { suoxuer } & \text { he } & \text { qiaomusiji } & \text { dou shi yuyanxuejia. } \\ \text { Saussure } & \text { CONJ } & \text { Chomsky } & \text { both be linguist }\end{array}$

'Saussure and Chomsky both be linguists.'

This sentence is perfectly felicitous with the bare copular shi, and it seems to be at odds with the analysis that assumes a covert tense that specifies for [PAST] and [NON-PAST] features in Chinese, which would render (10) as infelicitous.

In the next section, we seek to confirm these observations by using experimental methods. We adopt two psycholinguistic techniques, namely acceptability judgment and selfpaced reading, which are used to investigate the incremental update process during online language comprehension, and how it relates to or disassociates with the end product of language processing.

3. Processing lifetime effects. This section presents results from two experiments which investigate the offline and online processing of lifetime effects in English and Chinese.

\subsection{EXPERIMENT 1: ACCEPTABILITY JUDGEMENT}

Design \& Procedure We developed a set of experimental materials in which the lifetime information of two individuals in the context was manipulated such that both were living

\footnotetext{
${ }^{1}$ Note, however, that there is an asymmetry between the two tenses: lifetime inferences from the past tense are predicted to be less robust than those from the present tense, partially due to the contextual dependency of the English past tense (Mittwoch, 2008) and the possibility of coercing individual-level predicates into a stage-level reading in the past tense (Kratzer, 1995). For these reasons, we focus on the English present tense and the Chinese bare clauses in our study.
} 
(Living-Living), dead (Dead-Dead), or one was living the other was dead (Conjoin), with a total of 60 items. A sample item is given in Table $1^{2}$.
Living-Living
Dead-Dead
Conjoin

\begin{tabular}{clll}
\hline Lifetime & This house was built for & This house was built for & This house was built for \\
information & John, who is a local real & John, who passed away & John, who passed away \\
estate agent in town. The & last year. The one over & last year. The one over \\
one over there belongs to & there be- longed to his & there belongs to his \\
his brother, Bill, who & brother, Bill, who lived & brother, Bill, who now \\
now lives in Europe. & his whole life in Europe. & lives in Europe.
\end{tabular}

Critical

They are/shi both very handsome.

sentence

Table 1: sample material

The experiment was written in JavaScript and hosted on IbexFarm (Drummond, 2016). Twenty-four English-speaking participants were recruited on Amazon Mechanical Turk, and twenty-four native speakers of Chinese were recruited from the undergraduate and postgraduate communities at the Shanghai International Studies University ${ }^{3}$. All participants provided their written informed consent to participate in the experiment and received monetary compensation ${ }^{4}$.

Participants were asked to read each short passage, and then rate the critical sentence on a scale of 1-7, with 1 being "very unnatural" and 7 "perfectly fine". The three lifetime conditions were distributed in a Latin Square design, and participants were randomly assigned to one of the three lists. There was also a total number of 60 fillers.

Results \& Analysis In the English study, analysis of RTs per subject suggested that no subject should be removed. In the Chinese study, analysis of RTs per subject revealed one outlier. Together, trials whose reading times (RTs) were shorter than $2000 \mathrm{~ms}$ or more than 2.5 standard deviations above the mean were removed from further analysis, since RTs that fall out of these ranges do not suggest normal language processing. The methodological procedures established here were followed in subsequent experiments.

The means of the acceptability ratings for each condition in English and Chinese are summarised in Figure 1 and Figure 2, respectively:

\footnotetext{
${ }^{2}$ All materials were translated from English into Chinese and presented in simplified Chinese characters. Due to space limits, we only provide the English examples here, but all materials are provided in Appendix B and Appendix C in Chen (2017) and can be accessed online: https://osf.io/y7fub/

${ }^{3}$ Many thanks to Fuyun Wu for helping us host this experiment at the Shanghai International Studies University.

${ }^{4}$ All methods were approved by Social Sciences \& Humanities Inter-Divisional Research Ethics Committee at the University of Oxford.
} 


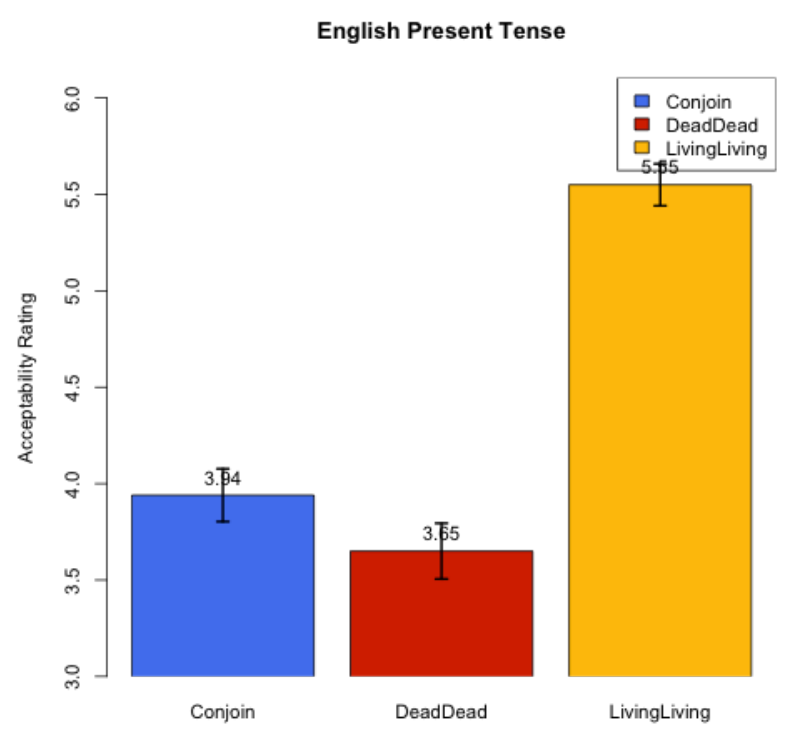

Figure 1. Ratings for English present tense

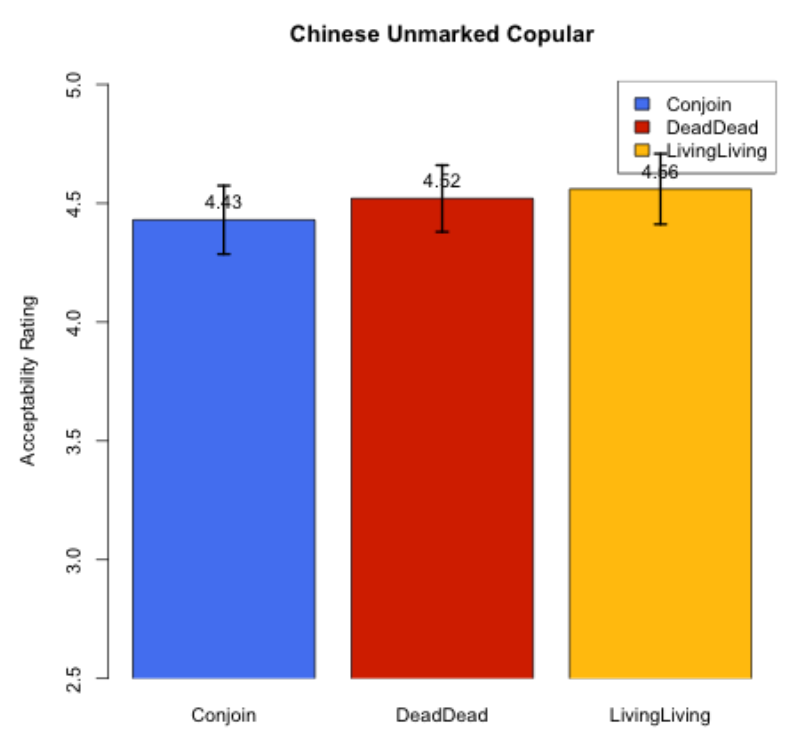

Figure 2. Ratings for Chinese bare clauses

Statistical analysis was carried out using linear mixed effect models in R (R Core Team, 2016), with the maximal random effect structure that allowed the model to converge. Lifetime information was coded as a fixed effect, whereas item and participant were coded as random effects. In the English present tense, there was a main effect of lifetime information, with the Living-Living condition being rated significantly higher than both the Dead-Dead condition and the Conjoin condition $(\mathrm{t}=4.207, \mathrm{p}<.001)$. With the Chinese bare clauses, however, there was no difference between the three lifetime conditions $(t=-0.093, p=.927)$.

The judgment data clearly shows that the Chinese bare clauses are not sensitive to a Past/Non-Past distinction, contrary to the prediction made by theories that assume covert past tense (e.g. Sybesma, 2007). Instead, Chinese bare clauses admit both past and present readings, as well as a simultaneous past-present reading ${ }^{5}$. However, the data presented so far is insufficient to conclude that Chinese is completely "tenseless", since these results can be equally accounted for by a non-future tense analysis of Chinese as it is the case that a currently dead and currently living individual are both in some sense non-future. It remains a possibility that Chinese simply possesses a different tense system from the one in English, e.g. a Future/Non-Future distinction.

Such speculations would predict that the online processing of contradictory lifetime inferences may still involve extra cost via an "online update" process, despite the superficially "tenseless" structure of the language. It becomes self-evident at this point that offline judgments are not sufficient in addressing all the questions raised so far, since they fail to elucidate how the

\footnotetext{
${ }^{5}$ There is, however, a potential alternative explanation worth considering: perhaps this conflict of tense features in contradictory lifetime inferences does exist, but it is resolved at the morpho-phonological level because the Chinese bare copular is a neutralized form of the two tense features (Pullum \& Zwicky, 1986). Taking the number agreement in English as an example: "John thinks that they/you , and Mary is quite sure that you/they, are going to be late." Here, the conjunctive construction is grammatical because the second person singular pronoun and the third person plural pronoun share an identical morph-phonological form, such that the conflict of features is resolved and does not lead to ungrammaticality. Note, however, that this could be analysed as a right node raising construction which licenses feature mismatches when the two conjuncts have different tenses, with the second conjunct controlling the morphology on the shared copular (Larson, 2012). This explanation is also not viable for our data because in the experimental design, we consistently used they rather than a conjoined NP construction in the subject position.
} 
incremental representation of tense may disassociate with the final representation thereof, especially when such an asymmetry is anticipated based on theoretical grounds. How does the processing of lifetime information unfold over time, and how can it inform us of the process of discourse update during online comprehension? Questions like these motivate the need to probe into the online processing of lifetime effects.

\subsection{EXPERIMENT 2: SELF-PACED READING}

Design \& Procedure Using Experiment 1 as a norming study, we selected the strongest 42 items to be included in Experiment 2. Sixty native speakers of English were recruited on Amazon Mechanical Turk; an additional thirty six participants were recruited from the University of Oxford undergraduate community. Sixty native speakers of Chinese were recruited from the undergraduate and postgraduate communities at Shanghai International Studies University. Participants received either monetary compensation or course credits for their time. Everything else followed Experiment 1.

The current experiment used a phrase-by-phrase, centered, serial visual presentation selfpaced reading design. Participants read each sentence as a series of word "chunks", seeing only one part of the sentence at a time, and they were instructed to move on to the next "chunk" by pressing the space bar at their own pace. Figure 3 illustrates how the sentences were split into "chunk":

This house was | built for John | who passed away | last year. | The one over there

| belonged to his brother, Bill, | who now lives | in Europe. | They are both | very

handsome. | Their relatives | are gathering together | next month for a reunion.

Figure 3. Word "chunks" of a trial

Critical sentences were followed by a spillover sentence that was kept consistent across all six conditions, e.g. Their relatives are gathering together next month, in order to capture any ongoing effects of temporal interpretation after presentation of the critical sentence. We carefully manipulated the spillover sentences such that they should not affect on the temporal interpretation of the previous critical sentences.

A multiple-choice comprehension question was given at the end of each trial in order to monitor if the participants were paying attention to the task. In addition, participants were forced to take a short break for 10 seconds every $20-25$ sentences, but they were advised to not pause during a trial.

Results \& Analysis $\quad$ On average, all participants in the English and the Chinese studies reported normal RTs. Six participants in the English experiment and four participants in the Chinese experiment were removed due to poor performance in the comprehension questions (below $75 \%$ accuracy).

We analysed the RT measurements on four critical regions, i.e. the individual-level predicate and the spillover regions. RTs for all critical regions are summarised in Table 2 for the English present tense, and in Table 3 for Chinese bare clauses (parentheses represent standard error by participants): 


\begin{tabular}{ccccc} 
& $\begin{array}{c}\text { Individual-level } \\
\text { predicate }\end{array}$ & Spillover 1 & Spillover 2 & Spillover 3 \\
\hline Living-Living & $596(13)$ & $593(13)$ & $543(12)$ & $577(12)$ \\
Dead-Dead & $610(14)$ & $571(13)$ & $533(10)$ & $610(16)$ \\
Conjoin & $653(17)$ & $626(15)$ & $558(13)$ & $610(15)$ \\
\hline
\end{tabular}

Table 2: RTs for all critical regions in the English present tense

\begin{tabular}{ccccc} 
& $\begin{array}{c}\text { Individual-level } \\
\text { predicate }\end{array}$ & Spillover 1 & Spillover 2 & Spillover 3 \\
\hline Living-Living & $638(21)$ & $572(16)$ & $539(16)$ & $576(16)$ \\
Dead-Dead & $643(21)$ & $571(17)$ & $549(16)$ & $644(23)$ \\
Conjoin & $642(20)$ & $580(15)$ & $563(15)$ & $633(21)$ \\
\hline
\end{tabular}

Table 3: RTs for all critical regions in Chinese bare clauses

RTs across the critical sentence and all spillover regions were illustrated in Figure 4 for the English data and in Figure 5 for the Chinese data:

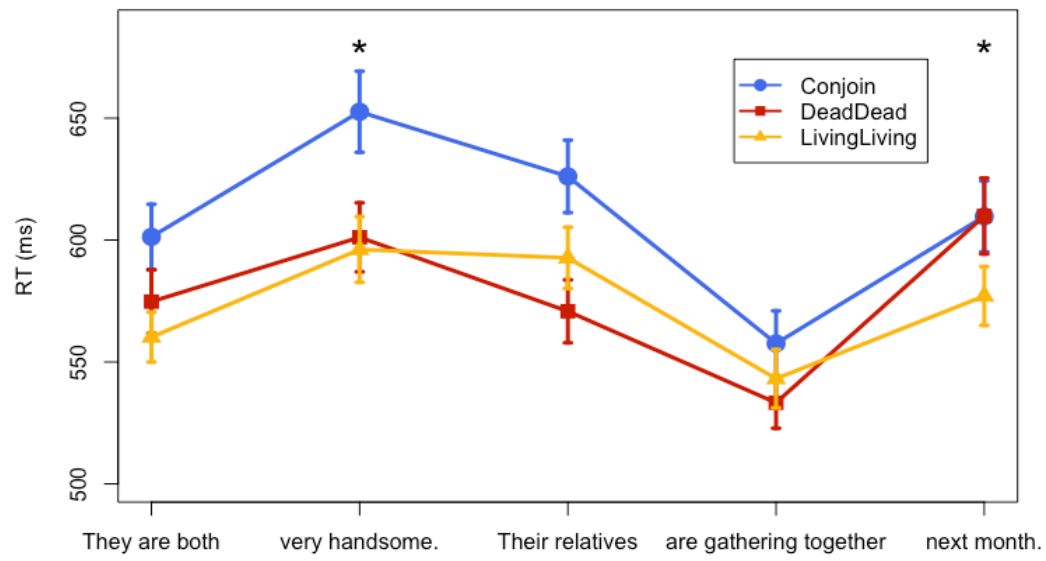

Figure 4. RT for the English present tense

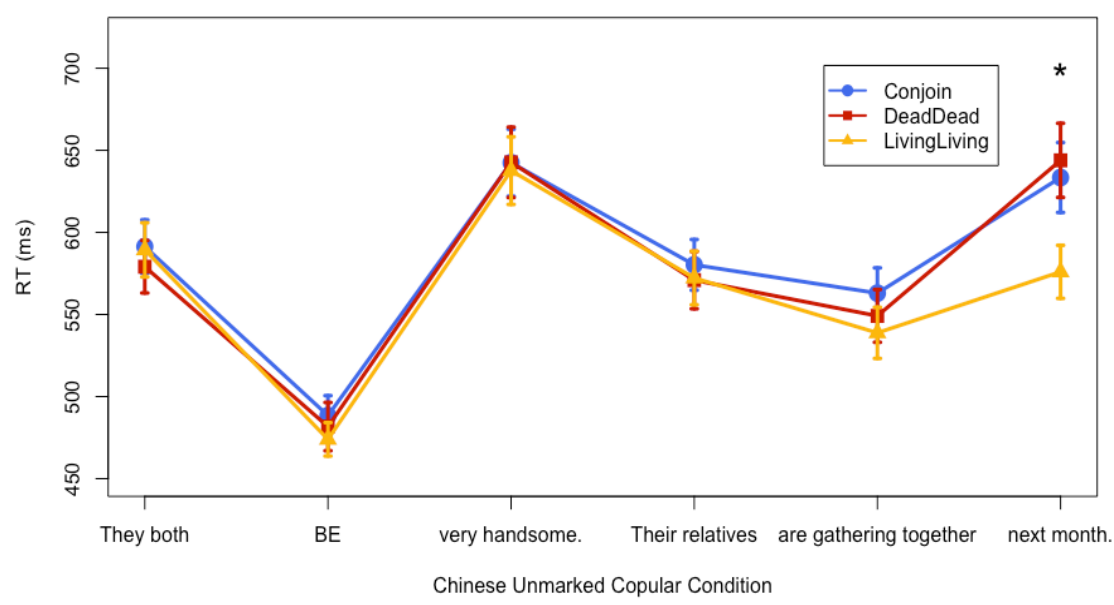

Figure 5. RTs for Chinese bare clauses 
In the English data, on the individual-level predicate region, RTs for the Conjoin condition were $43 \mathrm{~ms}$ longer than the Dead-Dead condition and 57ms longer than the Living-Living condition. Statistical analysis using linear mixed effect model suggests that the Conjoin condition was significantly different from the other two conditions on this region $(t=-3.007, p<.005)$. Additionally, on the $3^{\text {rd }}$ spillover region (see Figure 6), RTs for the Conjoin condition and the Dead-Dead condition were also a statistically significant difference from the Living-Living Condition $(t=2.195, p<.05)$. No significant effects were found on other regions. In the Chinese data, on the $3^{\text {rd }}$ spillover region (see Figure 7), RTs for the Conjoin condition and the Dead-Dead condition were $57 \mathrm{~ms}$ and $68 \mathrm{~ms}$ longer than the Living-Living condition respectively Statistical analysis using linear mixed effect model suggests this is a statistically reliable contrast $(\mathrm{t}=$ $2.210, \mathrm{p}<.05)$. No significant effects were found on other regions.

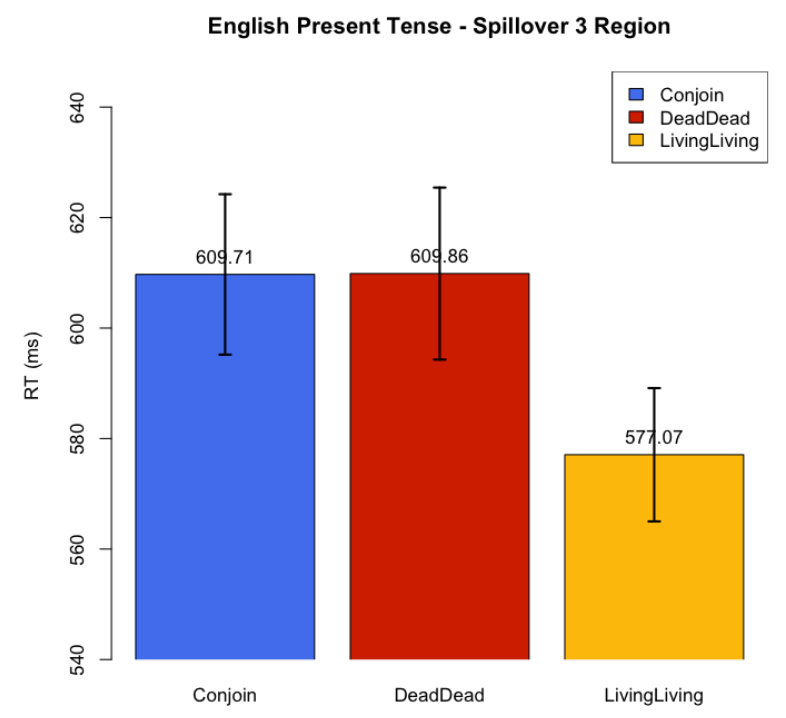

Figure 6. RTs on the English spillover region

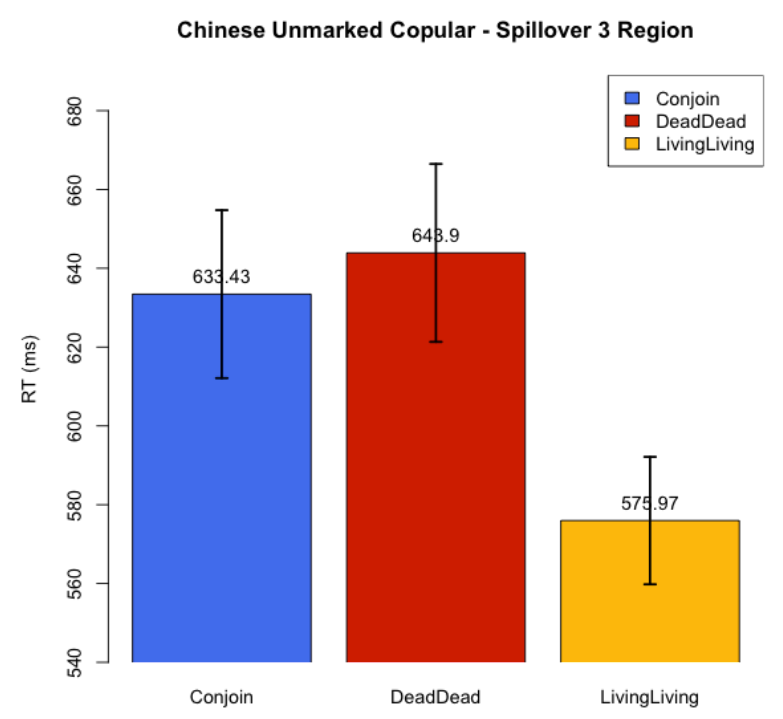

Figure 7. RTs on the Chinese spillover region

Recall that in Experiment 1, we observed an asymmetrical judgment pattern between English and Chinese: while English speakers judged sentences with contradictory lifetime inferences as significantly less acceptable than sentences with matching temporal information, Chinese speakers did not seem to find these sentences problematic. These results undermine the hypothesis that Chinese has a covert past tense. In Experiment 2, however, we observed sentence-final wrap-up effects in both English and Chinese: in the $3^{\text {rd }}$ spillover region, both English and Chinese participants showed reading time disruption, displaying a symmetrical pattern during online processing. Based on this, we speculate that it is unlikely for Chinese to be completely "tenseless". If Chinese bare clauses are not sensitive to any kind of tense distinction, then we would not expect to see any processing difficulty during the online comprehension of contradictory lifetime inferences in Chinese. Rather, results from online processing suggest that Chinese bare clauses involving one living and one dead individual - which presumably do not give rise to contradictory lifetime inferences - also elicited longer RTs.

This leaves us with the possibility that Chinese bare clauses have a non-future tense. Adopting the idea that this is the tense distinction in Chinese, we may explain the processing difficulty encountered by Chinese participants as a result of a "discourse update" process as the 
computation of temporal information unfolds in time: the processing cost involved in comprehending contradictory lifetime inferences may come from a clash of temporal intervals when establishing semantic representations, in which case an offline penalty is expected, as is the case for the English present tense. On the other hand, it may also be a result of taking extra computational steps in the "discourse update" process, in which case online processing difficulty does not necessarily translate into lower acceptability ratings, as we have seen in Chinese ${ }^{6}$.

While we have made some reasonable speculations based on the results in Experiment 2, these speculations are very much suggestive in nature. In the next section, we present some empirical observations from temporal interpretation in Chinese, which further supports a nonfuture tense analysis.

4. The non-future tense. The idea that Chinese has a Future/Non-Future tense distinction is supported by our observation of "forward lifetime effects" (Arche, 2006): when the subject involves one living and one yet-to-be-born individual, the bare copular shi cannot be used. For example, given the following context in (11), the continuation in (12) is infelicitous:

(11) Holly, a British actress, will give birth to her first baby in New York. Her assistant, Georgia, had her baby in California last month.

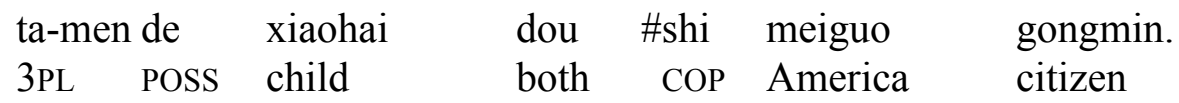

Intended: 'Their babies both be American citizens.'

Under a tenseless approach, no difference should be expected between (8) and (12). The infelicity of (12) suggests that a completely tenseless theory of Chinese is unlikely to hold; instead, the Chinese bare clauses may involve the projection of a T node with the [NONFUTURE] value, excluding a future reference when appearing in aspectually unmarked sentences. The nonfuture tense analysis has also been explored by Sun (2014), who observes that stative sentences with a bare clauses in Chinese can be used to "describe plural eventualities with more than one temporal location" (p. 205), allowing simultaneous past and present readings:

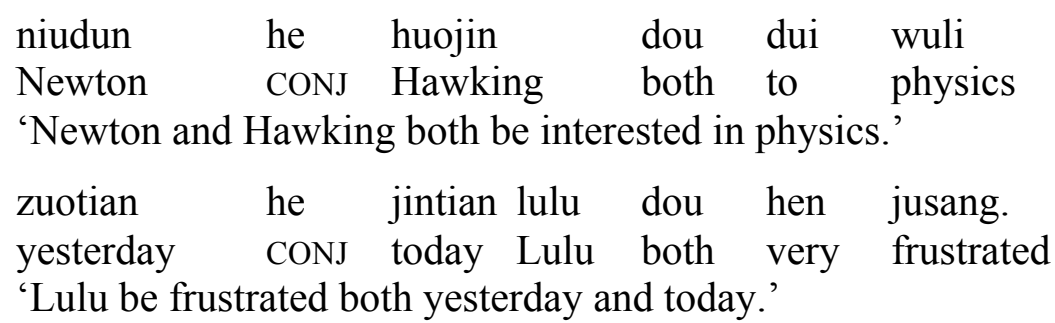

These examples show that the non-future tense is not restricted to you and the bare copular shi, but can also be extended to other types of predicates, including non-verbal ones. Based on these observations, she argues that Chinese has a morphologically null tense, NONFUT, which restricts the temporal reference of aspectually unmarked clauses to the non-future ${ }^{7}$.

The idea of assuming a covert non-future tense largely follows Matthewson's (2006) analysis on St'át'imcets, which involves a tense morpheme that is able to account for the absence of future readings in aspectually unmarked sentences "by means of a presupposition restricting the reference time to non-future values" (p. 699).

\footnotetext{
${ }^{6}$ For a detailed analysis of the "discourse update" process, see Chapter 4.2 in Chen (2017).

${ }^{7}$ See also Li (2016) for syntactic arguments in favor of a non-future T node in Chinese.
} 
Additional evidence for a Future/Non-Future tense distinction in Chinese comes from $\mathrm{Z}$. N. Huang's (2015) proposal for jiang, which he takes as a future tense morpheme that alternates with a zero non-future morpheme. His theoretical arguments largely build on the distribution and syntactic properties of jiang, but we will not elaborate on them here due to space limits.

5. Discussions and implications. In this paper, we presented evidence offline acceptability judgment which suggests that Chinese bare clauses do not have a Past/Non-Past distinction. Results from the online processing of contradictory lifetime inferences showed reading time disruption in both English and Chinese, suggesting that Chinese is unlikely to be entirely "tenseless" but may possess a tense node with a Future/Non-Future distinction, in line with many empirical observations.

The non-future tense analysis of Chinese calls for a re-analysis of a class of "tenseless" languages, as it questions whether such a homogeneous class actually exists. One implication is that some of these languages may resemble Chinese in having a Future/Non-Future distinction, while the others could be truly tenseless. An even stronger implication says that all superficially "tenseless" languages actually possess a Future/Non-Future distinction. The current study suggests that Chinese, and perhaps other so-called "tenseless" languages as well, possesses a tense system that distinguishes Future from Non-Future. This view challenges the commonlyheld misconception about tense as a split between Past and Non-Past, which possibly results from the focus on Indo-European languages in previous literature. A class of "tenseless" languages must be scrutinized with new care. The re-analysis of "tenseless" languages is worth pursing as it has an even broader bearing on certain fundamental issues, such as whether Tense Phrase is a universal syntactic category. The current study fits into the research agenda of identifying universal functional categories and the range of variation these categories allow for (Ritter and Wiltschko, 2014).

Future research may also pursue the possibility of re-analyzing superficially "tenseless" languages as having a Future/Non-Future tense distinction covertly. If this possibility turns out to be tenable, then a new typology of tense systems presents itself: in languages of the world, the unmarked tense includes the interval now while the marked tense is semantically 'not now', which may specify either a past or a future reference. We propose that this specification is subject to cross-linguistic variation. Morpho-syntactically, languages typically have a tense system with binary feature distinctions, with a split between either Past/Non-Past or Future/NonFuture (See Figure 8). These features may be encoded overtly or covertly; some languages can lack the overt morpho-phonological marking of the values of these features, but Tense Phrase exists universally in the hierarchical structure of all languages, as part of the finite set of fundamental principles provided by Universal Grammar to enable the acquisition of temporal references in language.

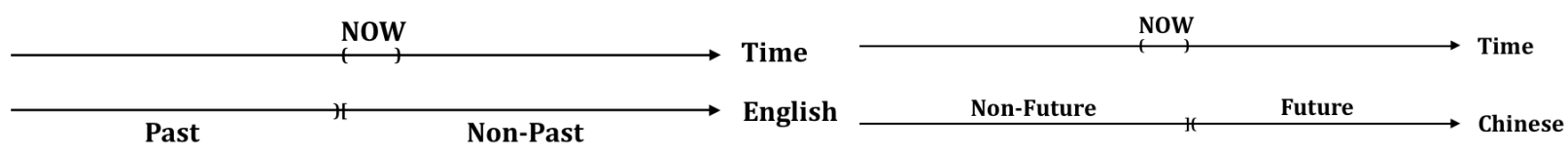

Figure 8. Parametric settings for different tense systems

Several predictions can be made at this point. First, based on our findings about contradictory lifetime effects and (forward) lifetime effects in Chinese, similar observations should be expected in other superficially "tenseless" languages. A covert non-future tense analysis will be consistent with the lack of contradictory lifetime effects but the presence of 
"forward lifetime effects" in a language. Second, all "tenseless" languages can be alternatively analysed as possessing a covert tense (e.g. Tonhauser, 2011). If no empirical evidence contradicts the non-future tense analysis, then the remaining debate is whether this line of analysis is theoretically desirable. Finally, our proposed typology of tense also makes interesting predictions about impossible and improbable tenses: a Present/Non-Present distinction is not a possible tense, because the temporal reference of a tense cannot be separated continuously by the NOW interval. Such a system would violate Comrie'a (1985) condition that tenses must reflect "a continuity". Note, however, the possible three-way feature distinction between Past/Present/Future is, as far as we know, unattested. This raises the question of whether such a tense system is incompatible with UG (because there is no [PRESENT] feature) or whether it is just historical accident. We leave these questions for future research.

Time is an immediate and fundamental human experience, "a universal constant" stored in our linguistic system. As such, temporal relations are given as "part of our world knowledge" (Klein, 1994, p.121). Tense as a potential structural universal is a window into the human language; in particular, languages with distinct tense systems, such as English and Chinese, provide invaluable insights into the processing of tense and how it reflects discourse update as a dynamic process, with this study being merely a preliminary sketch.

\section{References}

Anderson, J. 1973. The ghost of times past. Foundations of Language, 9(4). 481- 491.

Arche, M. J. 2006. Individuals in time: tense, aspect and the individual/stage distinction. Amsterdam/Philadelphia: John Benjamins Publishing. http://doi.org/10.1075/la.94

Chen, S. Y. 2017. Processing Tenses for the Living and the Dead: A Psycholinguistic Investigation of Lifetime Effects in Tensed and "Tenseless" Languages. Oxford, UK: University of Oxford MPhil thesis.

Dowty, D. R. 1979. Word meaning and Montague Grammar: the semantics of verbs and times in Generative Semantics and in Montague's PTO. Reidel. http://doi.org/10.1007/978-94-0099473-7

Drummond, A. 2016. IbexFarm (Version 0.3.9). Retrieved from http://spellout.net/ibexfarm/

Grano, T. 2014. Control Without Finiteness Contrasts: PRO, Aspect, and Complementation Size in Mandarin Chinese. Unpublished manuscript.

Grano, T. 2017. Finiteness contrasts without Tense? A view from Mandarin Chinese. Journal of East Asian Linguistics, 26(3). 259-299. https://doi.org/10.1007/s10831-017-9159-8

Huang, C. T. J. 1998. Logical relations in Chinese and the theory of grammar. Taylor \& Francis.

Huang, Z. N. 2015. On syntactic tense in Mandarin Chinese. NACCL 27. 406-423. Los Angeles: UCLA.

Husband, E. M. 2012. On the compositional nature of states. Amsterdam/Philadelphia: John Benjamins Publishing. http://doi.org/10.1075/la.188

Jäger, G. 2001. Topic-comment structure and the contrast between stage-level and individuallevel predicates. Journal of Semantics, 18(2). 83-126. https://doi.org/10.1093/jos/18.2.83

Klein, W. 1994. Time in language. London, UK: Routledge.

Klein, W., Li, P., \& Hendriks, H. 2000. Aspect and assertion in Mandarin Chinese. Natural Language \& Linguistic Theory, 18(4), 723-770. https://doi.org/10.1023/A:1006411825993

Kratzer, A. 1995. Individual-level predicates. In G. N. Carlson \& F. J. Pelletier (eds.), The generic book. 125-175. University of Chicago Press. 
Lecarme, J. 2004. Tense in nominals. In J. Gúeron \& J. Lecarme (eds.), The syntax of time. 441476. Cambridge, MA: MIT Press.

Larson, B. (2012). A dilemma with accounts of right node raising. Linguistic Inquiry, 43(1). 143150. https://doi.org/10.1162/LING_a_00078

Li, N. 2016. T(ense) in Mandarin Chinese: Form and Meaning. Ithaca, NY: Cornell University dissertation.

Lin, J. W. 2003. Temporal reference in Mandarin Chinese. Journal of East Asian Linguistics. 12(3). 259-311. https://doi.org/10.1023/A:1023665301095

Lin, J. W. 2006. Time in a language without tense: The case of Chinese. Journal of Semantics, 23(1). 1-53. https://doi.org/10.1093/jos/ffh033

Lin, J. W. 2010. A tenseless analysis of Mandarin Chinese revisited: a response to Sybesma 2007. Linguistic Inquiry, 41(2). 305-329. https://doi.org/10.1162/ling.2010.41.2.305

Lin, J. W. 2012. Tenselessness. In R. I. Binnick (ed.), The Oxford Handbook of Tense and Aspect. 669-695. Oxford, UK: Oxford University Press.

Lin, T. H. 2011. Finiteness of clauses and raising of arguments in Mandarin Chinese. Syntax, 14(1). 48-73. http://dx.doi.org/10.1111/j.1467-9612.2010.00145.x

Lin, T. H. 2012. Multiple-modal constructions in Mandarin Chinese and their finiteness properties. Journal of Linguistics, 48(1). 151-186.

https://doi.org/10.1017/S0022226711000272

Lin, T. H. 2015. Tense in Mandarin Chinese sentences. Syntax, 18(3). 320-342. https://doi.org/10.1111/synt.12032

Magri, G. 2009. A theory of individual-level predicates based on blind mandatory scalar implicatures. Natural Language Semantics, 17(3). 245-297. https://doi.org/10.1007/s11050-009-9042-x

Matthewson, L. 2001. Quantification and the nature of cross-linguistic variation. Natural Language Semantics, 9(2). 145-189. https://doi.org/10.1023/A:1012492911285

Matthewson, L. 2006. Temporal semantics in a superficially tenseless language. Linguistics and Philosophy, 29(6). 673-713. https://doi.org/10.1007/s10988-006-9010-6

Mittwoch, A. 2008. Tenses for the living and the dead: lifetime inferences reconsidered. In S. D. Rothstein (ed.), Theoretical and cross-linguistic approaches to the semantics of aspect. 167187. Amsterdam/Philadelphia: John Benjamins Publishing.

Musan, R. I. 1995. On the temporal interpretation of noun phrases. Cambridge, MA: Massachusetts Institute of Technology dissertation.

Musan, R. I. 1997. Tense, predicates, and lifetime effects. Natural Language Semantics, 5(3). 271-301. https://doi.org/10.1023/A:1008281017969

Pullum, G. K., \& Zwicky, A. M. (1986). Phonological resolution of syntactic feature conflict. Language, 62(4). 751-773. https://doi.org/10.2307/415171

R Core Team. 2016. R: a language and environment for statistical computing. R Foundation for Statistical Computing. Vienna, Austria. Retrieved from http://www.R-project.org/

Reichenbach, H. 1971. The direction of time. Berkeley: University of California Press.

Ritter, E. \& Wiltschko, M. 2014. The composition of INFL: an exploration of tense, tenseless languages, and tenseless constructions. Natural Language \& Linguistic Theory, 32. 13311376. https://doi.org/10.1007/s11049-014-9248-6

Roy, I. 2013. Nonverbal predication: copular sentences at the syntax-semantics interface.

Oxford, UK: Oxford University Press.

https://doi.org/10.1093/acprof:oso/9780199543540.001.0001 
Smith, C. S. 2008. Time with and without tense. In J. Gúeron \& J. Lecarme (eds.), Time and modality. 227-249. Springer.

Smith, C. S. \& Erbaugh, M. S. 2005. Temporal interpretation in Mandarin Chinese. Linguistics, 43(4). 713-756. https://doi.org/10.1515/ling.2005.43.4.713

Sun, H. 2014. Temporal construals of bare predicates in Mandarin Chinese. Leiden, the Netherlands: Leiden University dissertation.

Sybesma, R. P. E. 2007. Whether we tense-agree overtly or not. Linguistic Inquiry, 38(3). 580587. https://doi.org/10.1162/ling.2007.38.3.580

Thomas, G. 2012. Temporal implicatures. Cambridge, MA: Massachusetts Institute of Technology dissertation. 